\title{
Analisa Pengaruh Variasi Temperatur Pemadatan Campuran Laston Lapis Antara (AC-BC) dengan Menggunakan Aspal Modifikasi
}

\author{
Machsus Machsus ${ }^{1, *}$, Amalia Firdaus Mawardi ${ }^{1}$, Mohamad Khoiri ${ }^{1}$, Rachmad Basuki ${ }^{1}$, Farraz Haidar \\ Akbar ${ }^{1}$ \\ Departemen Teknik Infrastruktur Sipil, Institut Teknologi Sepuluh Nopember, Surabaya ${ }^{1}$ \\ Koresponden*, Email: machsusfawzy@gmail.com
}

\begin{tabular}{|c|c|c|}
\hline & Artikel & Abstract \\
\hline Diajukan & 4 Desember 2019 & ns in compaction temperature \\
\hline perbaiki & 4 Desember 2019 & between the Laston Lapis Intermediate Mixture $(A C-B C)$ using modified asphalt that utilizes \\
\hline Disetujui & 30 Januari 2020 & $\begin{array}{l}\text { Polyethylene Terephthalate (PET) plastic waste. The variation of compaction temperature used } \\
\text { is } 100^{\circ} \mathrm{C}-180^{\circ} \mathrm{C} \text { with a temperature interval of } 10^{\circ} \mathrm{C} \text {. The method used in } \mathrm{AC}-\mathrm{BC} \text { mixing is the } \\
\text { wet method. Preparation and testing of test specimens are carried out in } 2 \text { stages, namely } \\
\text { making test specimens without addition and with the addition of } P E T \text {. The results showed that } \\
\text { the optimum temperature of conventional asphalt compaction was } 160^{\circ} \mathrm{C} \text { and stability of }\end{array}$ \\
\hline $\begin{array}{l}\text { Keywords: } \\
\text { BC, marsh } \\
\text { temperatu }\end{array}$ & $\begin{array}{l}\text { e terephthalate, } A C \text { - } \\
\text { ristic, compaction }\end{array}$ & $\begin{array}{l}1602.10 \mathrm{kN} \text { and } M Q \text { was } 376.71 \mathrm{~kg} / \mathrm{mm} \text {. In the modified asphalt with the addition of PET type } \\
\text { plastic obtained an optimum compaction temperature of } 180^{\circ} \mathrm{C} \text { with a stability value of } 2547.27 \\
\mathrm{kN} \text { and } M Q \text { of } 629.91 \mathrm{~kg} / \mathrm{mm} \text {. }\end{array}$ \\
\hline
\end{tabular}

\begin{abstract}
Abstrak
Makalah ini bertujuan memberikan analisa pengaruh variasi temperatur pemadatan Campuran Laston Lapis Antara (AC-BC) dengan menggunakan aspal modifikasi yang memanfaatkan limbah plastik jenis Polyethylene Terephthalate (PET). Variasi temperatur pemadatan yang digunakan yaitu $100^{\circ} \mathrm{C}-180^{\circ} \mathrm{C}$ dengan interval temperature $10^{\circ} \mathrm{C}$. Metode yang digunakan dalam pencampuran $\mathrm{AC}-\mathrm{BC}$ ini adalah metode basah. Pembuatan dan pengujian benda uji dilakukan dalam 2 tahap, yakni pembuatan benda uji tanpa penambahan dan dengan penambahan PET. Hasilnya menunjukkan bahwa temperatur optimum pemadatan aspal konvensional $160^{\circ} \mathrm{C}$ dan stabilitas $1602,10 \mathrm{kN}$ dan MQ sebesar $376,71 \mathrm{~kg} / \mathrm{mm}$. Pada aspal modifikasi dengan penambahan plastik tipe PET didapatkan temperatur optimum pemadatan $180^{\circ} \mathrm{C}$ dengan nilai stabilitas $2547,27 \mathrm{kN}$ dan MQ sebesar $629,91 \mathrm{~kg} / \mathrm{mm}$.
\end{abstract}

Kata kunci: polyethylene terephthalate, $A C$ $B C$, karakteristik marshall, temperatur pemadatan tersebut diduga mencemari lautan. Data tersebut menunjukkan bahwa Indonesia merupakan negara dengan jumlah pencemaran limbah plastik ke laut terbesar kedua di dunia. China memimpin dengan tingkat pencemaran limbah plastik ke laut sekitar 1,23-3,53 juta ton/tahun[3].

Kementerian Pekerjaan Umum dan Perumahan Rakyat (PUPR) terus mengembangkan teknologi campuran aspal plastik. Penerapan teknologi aspal plastik merupakan upaya pemerintah dalam pengurangan limbah plastik. Penambahan limbah plastik PET dapat meningkatkan mutu pada campuran AC-BC dan menghemat biaya konstruksi infrastruktur jalan[1],[4].

Proses pembuatan campuran aspal modifikasi dapat dilakukan dengan dua cara, yaitu cara basah (wet process) dan cara kering (dry process). Cara basah dilakukan dengan mencampurkan mencampurkan limbah plastik dengan aspal untuk melakukan modifikasi terhadap aspal. Cara kering dilakukan dengan mencampurkan limbah plastik dengan Diperkirakan sekitar 0,48-1,29 juta ton dari limbah plastik 
agregat panas kemudian dicampur dengan aspal untuk memodifikasi agregat[1],[9].

Pembuatan campuran aspal modifikasi dengan penambahan plastik PET membutuhkan temperatur tinggi[4]. Oleh karena itu, perlu dilakukan penelitian mengenai pengaruh variasi temperatur pemadatan Campuran Laston Lapis Antara (AC-BC) terhadap karakteristik Marshall dengan menggunakan aspal modifikasi. Hal ini penting untuk mengetahui temperatur pemadatan minimum dan optimum pada Campuran AC-BC agar memenuhi spesifikasi umum Bina Marga 2010[5].

\section{Material dan Metode}

Penelitian ini menggunakan beberapa jenis ukuran material agregat yaitu agregat ukuran (10-20 mm), (10-10 $\mathrm{mm}),(5-10 \mathrm{~mm})$, dan abu batu dengan ukuran $(0-5 \mathrm{~mm})$. Jenis aspal yang digunakan adalah aspal dengan penetrasi 60/70. Proporsi campuran menggunakan proporsi dari penelitian sebelumnya yang sudah dilakukan oleh Derina Septia Pertiwi 2018. Alat - alat yang digunakan meliputi 1 set alat uji sifat fisik agregat, 1 set alat uji aspal, serta alat uji marshall.

Botol plastik bekas tape PET digunakan sebagai aditif pengubah dalam campuran aspal panas. Untuk tujuan ini, limbah botol plastic PET dibersihkan dan dipotong kecilkecil dan dihancurkan dengan alat penacacah (crusher) khusus untuk plastik.

Metode dalam penelitian ini meliputi pengujian material, pengujian aspal, pembuatan serta pengujian kadar aspal optimum dan pembuatan serta pengujian aspal plastik. Pencampuran limbah plastik menggunakan metode basah (wet process). Variasi temperatur pemadatan yang digunakan $100^{\circ} \mathrm{C}, 110^{\circ} \mathrm{C}, 120^{\circ} \mathrm{C}, 130^{\circ} \mathrm{C}, 140^{\circ} \mathrm{C}, 150^{\circ} \mathrm{C}, 160^{\circ} \mathrm{C}, 170^{\circ} \mathrm{C}$, dan $180^{\circ} \mathrm{C}$.

Tahapan analisa dan pembahasan pada penelitian ini meliputi uji karakteristik marshall yaitu nilai kepadatan, VIM, VMA, VFA, Stabilitas, Flow, dan Marshall Quotient. Jika tahapan analisa dan pembahasan telah selesai maka dapat dilakukan penarikan kesimpulan.

\section{Hasil dan Pembahasan}

Pengaruh variasi temperature pemadatan Campuran Laston Lapis Antara (AC-BC) dengan menggunakan aspal modifikasi, yakni dengan penambahan limbah plastik PET dapat dilihat pada perubahan karakteristik Marshall. Karakteristik Marshall pada penelitian ini dapat dilihat dari: nilai VIM (Void in Mix), VMA (Void in Mineral Aggregate), VFA (Void Filled Asphalt), Flow, Stabilitas, and MQ.



Gambar 1. Grafik pengaruh variasi temperatur pemadatan terhadap VIM

Gambar 1 menunjukkan pengaruh variasi temperatur pemadatan Campuran Laston Lapis Antara (AC-BC) terhadap nilai VIM. Temperatur pemadatan campuran AC-BC konvensional dan modifikasi yang semikin tinggi berpengaruh terhadap nilai VIM yang cenderung menurun. Berdasarkan Spesifikasi Umum Bina Marga 2010 ditetapkan nilai VIM untuk AC-BC memiliki syarat minimum 3\% dan maksimum 5\%. Untuk itu, pada AC-BC konvensional hanya pada temperatur pemadatan $150^{\circ} \mathrm{C}$ hingga $170^{\circ} \mathrm{C}$ yang memenuhi, sedangkan pada $\mathrm{AC}-\mathrm{BC}$ konvensional hanya pada temperatur pemadatan $150^{\circ} \mathrm{C}$ hingga $180^{\circ} \mathrm{C}$ yang memenuhi. Nilai VIM ini menunjukkan bahwa pada temperatur di bawah $150^{\circ} \mathrm{C}$ tidak memenuhi spesifikasi. Pada temperatur pemadatan rendah aspal sulit menyelimuti agregat, sehingga campuran aspal dan agregat tidak homogen[5],[6].

Gambar 1 juga memperlihatkan bahwa nilai VIM campuran $\mathrm{AC}-\mathrm{BC}$ modifikasi cenderung lebih tinggi dibanding AC-BC konvensional. Hal ini disebabkan karena kadar aspal yang seharusnya mengisi rongga dalam campuran terhalang oleh plastik. Akibatnya prosentase rongga dalam campuran menjadi semakin banyak. Rongga yang tidak terisi oleh aspal ini mengakibatkan pori-pori dalam campuran semakin banyak. Olek karena itu, campuran AC-BC modifikasi tidak kedap air. Disamping itu, campuran AC-BC modifikasi menjadi lebih mudah crack, akibat proses oksidasi[4],[7].

Selanjutnya pada Gambar 2 dapat dilihat pengaruh variasi temperatur pemadatan terhadap VMA, baik pada pengujian campuran AC-BC konvensional maupun modifikasi. Grafik tersebut menggambarkan bahwa peningkatan temperatur pemadatan berpengaruh terhadap menurunnya nilai VMA. Pada Gambar 2 juga ditunjukkan bahwa nilai VMA untuk semua variasi temperatur pemadatan memenuhi spesifikasi umum Bina Marga 2010 yaitu minimum 14\% untuk AC-BC. Nilai VMA yang rendah pada temperatur 
pemadatan tinggi dikarenakan campuran AC-BC mengalami pemadatan yang optimal. Prosentase rongga dalam mineral agregat menjadi sedikit, karena terisi aspal, dan akibatnya lekatan butiran antar agregat menjadi semakin baik[5],[6].



Gambar 2. Grafik Pengaruh Variasi Temperatur Pemadatan Terhadap VMA

Gambar 2 juga memperlihatkan bahwa nilai VMA campuran AC-BC modifikasi lebih rendah daripada AC-BC konvensional. Penambahan plastik dapat menghalangi kadar aspal yang seharusnya mengisi rongga dalam mineral agregat. Semakin banyak rongga dalam mineral agregat yang tidak terisi aspal mengakibatkan mudah lepasnya ikatan butiran antar agregat[7],[8].

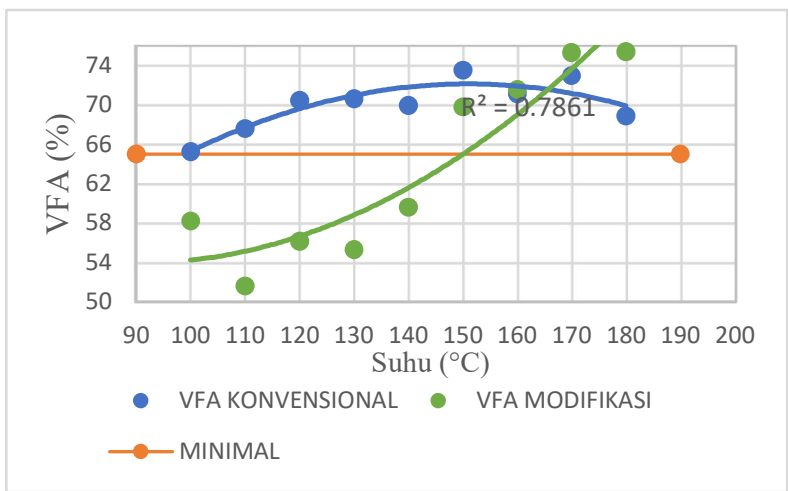

Gambar 3. Grafik Pengaruh Variasi Temperatur Pemadatan Terhadap VFA

Gambar 3 memperlihatkan pengaruh variasi temperatur pemadatan terhadap VFA pada campuran AC-BC konvensional dan modifikasi. Grafik tersebut menunjukkan bahwa peningkatan temperatur pemadatan berdampak terhadap nilai VFA yang cenderung meningkat. Berdasarkan Spesifikasi Umum Bina Marga 2010, disyaratkan bahwa nilai VFA untuk AC-BC memiliki syarat minimum 65\%. Data menunjukkan bahwa semua nilai VFA pada varias temperatur pemadatan pada AC-BC konvensional memenuhi spesifikasi.
Namun, pada AC-BC modifikasi yang memenuhi spesifikasi hanya pada temperatur pemadatan $150^{\circ} \mathrm{C}$ hingga $180^{\circ} \mathrm{C}$. Pada temperatur pemadatan AC-BC yang rendah diperoleh nilai VFA juga rendah. Artinya prosentase rongga yang terisi aspal rendah. Dengan kata lain, jumlah pori-pori yang banyak, sehingga campuran tersebut tidak kedap air[5],[6].

Gambar 3 juga menunjukkan nilai VFA campuran AC$\mathrm{BC}$ modifikasi lebih rendah dibanding AC-BC konvensional. Kondisi ini terjadi karena penambahan plastik menghalangi pengisian rongga dalam campuran dengan aspal. Akibatnya rongga yang tidak terisi aspal semakin banyak, sehingga campuran AC-BC menjadi porus[4].

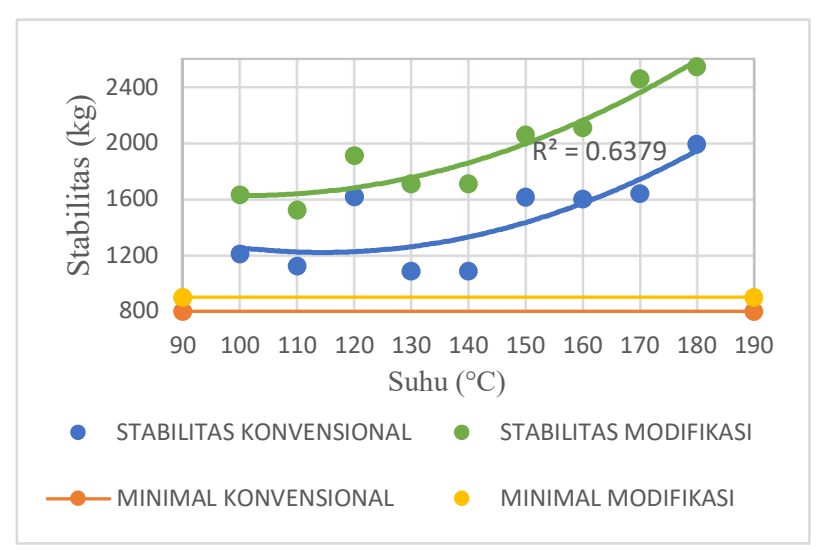

Gambar 4. Grafik Pengaruh Variasi Temperatur Pemadatan Terhadap Stabilitas

Gambar 4 menunjukkan pengaruh variasi temperatur pemadatan terhadap nilai stabilitas campuran AC-BC, baik konvensional maupun modifikasi. Grafik tersebut menunjukkan bahwa jika temperatur pemadatan maka stabilitasnya juga meningkat. Hal ini karena temperatur pemadatan yang tinggi mengakibatkan campuran AC-BC mengalami pemadatan optimal. Posisi antar partikel dalam campuran saling mengunci sehingga daya ikatnya semakin kuat, maka nilai stabilitasnya menjadi semakin tinggi[6],[9].

Gambar 4 juga memperlihatkan bahwa nilai stabilitas AC-BC modifikasi lebih tinggi daripada AC-BC konvensional. Hal ini disebabkan plastik yang ditambahkan berbentuk serat bersudut dan agregat yang terselimuti aspal saling mengunci dengan baik. Stabilitas AC-BC modifikasi lebih tinggi karena posisi agregat menjadi lebih stabil dan tidak mudah bergeser dari tempatnya ketika diberi beban[4],[9].

Gambar 5 menunjukkan pengaruh variasi temperatur pemadatan terhadap flow pada pengujian campuran AC-BC konvensional dan modifikasi. Data tersebut menunjukkan bahwa peningkatan temperatur pemadatan berdampak 
terhadap menurunnya nilai Flow. Berdasarkan Spesifikasi Umum Bina Marga 2010 dipersyarakan untuk campuran ACBC nilai Flow berada pada rentang antara $2 \mathrm{~mm}-4 \mathrm{~mm}$. Hasil pengujian Flow ini menunjukkan bahwa pada campuran AC-BC konvensional hanya pada temperatur pemadatan $160^{\circ} \mathrm{C}$ yang memenuhi spesifikasi. Namun, untuk campuran AC-BC modifikasi hanya pada temperatur pemadatan $180^{\circ} \mathrm{C}$ yang memenuhi spesifikasi[5].



Gambar 5. Grafik Pengaruh Variasi Temperatur Pemadatan Terhadap Flow

Flow yang terlalu tinggi maupun terlalu rendah tidak baik untuk campuran AC-BC. Nilai Flow yang terlalu tinggi mengindikasikan campuran yang bersifat plastis, dan lebih mudah mengalami deformasi akibat beban. Sementara, Flow yang terlalu rendah mengisyaratkan campuran tersebut memiliki banyak rongga tidak terisi aspal melampaui batas normal. Hal ini terjadi jika kandungan aspal terlalu rendah sehingga berpotensi menimbulkan retak dini, dan durabilitas rendah[5],[6].

Gambar 5 juga menunjukkan bahwa nilai Flow campuran AC-BC konvensional lebih tinggi dibandingkan dengan campuran AC-BC modifikasi. Kondisi ini terjadi karena kadar aspal pada campuran AC-BC konvensional lebih banyak dibanding AC-BC modifikasi. Kadar aspal yang lebih banyak mengakibatkan campuran AC-BC menjadi lunak dan nilai pelelehan meningkat[4],[9].

Gambar 6 menunjukkan pengaruh temperatur pemadatan campuran AC-BC konvensional dan modifikasi terhadap nilai Marshall Quotient (MQ). Nilai MQ mengalami peningkatan bilamana temperatur pemadatan dinaikkan. Berdasarkan Spesifikasi Umum Bina Marga 2010 ditetapkan nilai MQ minimal $250 \mathrm{~kg} / \mathrm{mm}$ untuk campuran AC-BC[5].

Hasil perhitungan MQ pada campuran $\mathrm{AC}-\mathrm{BC}$ konvensional hanya pada temperatur pemadatan $150^{\circ} \mathrm{C}$ hingga $180^{\circ} \mathrm{C}$ yang memenuhi spesifikasi, sedangkan pada AC-BC modifikasi hanya pada temperatur pemadatan $120^{\circ} \mathrm{C}$ hingga $180^{\circ} \mathrm{C}$ yang memenuhi spesifikasi. Penyebab meningkatnya nilai MQ pada temperatur pemadatan tinggi adalah tingginya stabilitas pada temperatur tersebut. Pada kondisi ini campuran AC-BC semakin kaku, sementara nilai Flow yang dihasilkan rendah. Dari grafik juga diketahui bahawa nilai MQ campuran AC-BC modifikasi lebih tinggi daripada AC$\mathrm{BC}$ konvensional[3],[5].



Gambar 6. Grafik pengaruh variasi temperatur pemadatan terhadap Marshall Quotient

\section{Simpulan}

Berpijak dari latar belakangan permasalahan, literatur review, hasil dan pembahasan dapat diambil beberapa kesimpulan, sebagai berikut:

1. Peningkatan temperatur pemadatan pada campuran ACBC konvensional dan modifikasi berpengaruh terhadap karakteristik Marshall, dimana nilai VFA, Stabilitas, dan MQ juga meningkat, sedangkan nilai VIM, VMA, dan Flow mengalami penurunan;

2. Hasil uji karakteristik Marshall diketahui bahwa campuran AC-BC konvensional memiliki nilai VFA, dan Flow yang lebih tinggi dibanding campuran AC-BC modifikasi, sedangkan untuk nilai VIM, VMA, dan Stabilitas lebih rendah;

3. Pada campuran AC-BC konvensional diperoleh temperatur minimum sebesar $150^{\circ} \mathrm{C}$ dan temperatur optimum sebesar $170^{\circ} \mathrm{C}$, sedangkan pada AC-BC modifikasi diperoleh temperatur minimum $150^{\circ} \mathrm{C}$ dan optimum sebesar $180^{\circ} \mathrm{C}$.

\section{Daftar Pustaka}

[1] I. Susanto and N. Suaryana, "Evaluasi Kinerja Campuran Beraspal Lapis Aus (AC-WC) dengan Bahan Tambah Limbah Plastik Kresek," J. Apl. Tek. Sipil, vol. 17, no. 2, pp. 27-36, 2019. 
[2] R. K. Padhan and A. A. Gupta, "Preparation and evaluation of waste PET derived polyurethane polymer modified bitumen through in situ polymerization reaction," Constr. Build. Mater., vol. 158, pp. 337-345, 2018.

[3] J. R. Jambeck et al., "Plastik waste inputs from land into the ocean," 2015.

[4] P. E. Purnamasari and F. Suryaman, "Pengaruh Penggunaan Limbah Botol Plastik Sebagai Bahan Tambah Terhadap Karakteristik Lapis Aspal Beton (Laston)," Konf. Nas. Tek. Sipil 4 (KoNTekS 4), vol. 4, no. KoNTekS 4, pp. 2-3, 2010.

[5] Dirjen Bina Marga, "Spesifikasi Umum Bidang Jalan dan Jembatan Revisi 3," Kementrian Pekerjaan Umum, Indonesia, 2010.

[6] B. Raharjo, P. Pratomo, and H. Ali, "Pengaruh Suhu Pemadatan Campuran Untuk Perkerasan Lapis Antara (AC-BC) Campuran aspal panas merupakan salah satu jenis dari lapis perkerasan konstruksi," JSRDD, vol. 4, no. 1, pp. 43-50, 2016.

[7] A. O. Sojobi, S. E. Nwobodo, and O. J. Aladegboye, "Recycling of polyethylene terephthalate (PET) plastic bottle wastes in bituminous asphaltic concrete," Cogent Eng., vol. 3, no. 1, pp. 1-28, 2016.

[8] L. Widojoko and P. E. Purnamasari, "Study the Use of Cement and Plastic bottle Waste as Ingredient Added to the Asphaltic Concrete Wearing Course," Procedia - Soc. Behav. Sci., vol. 43, pp. 832-841, 2012.

[9] A. Hassani, H. Ganjidoust, and A. A. Maghanaki, "Use of plastic waste (poly-ethylene terephthalate) in asphalt concrete mixture as aggregate replacement," Waste Manag. Res., vol. 23, no. 4, pp. 322-327, 2005. 
